\title{
Equipotent dose of levobupivacaine reduce the incidence of instrumental vaginal delivery when compared to ropivacaine during epidural labour analgesia

\author{
P Rani ${ }^{1}$, R Surya ${ }^{2}$, Annie J Sheeba ${ }^{3 *}$, S Parthasarathy ${ }^{1}$, Hemanth Kumar Vadlamudi Reddy ${ }^{4}, T$ \\ Sivashanmugam 4 \\ Associate Professor ${ }^{1}$, Resident ${ }^{2}$, Assistant Professor ${ }^{3 *}$, Professor ${ }^{4}$, Department of Anaesthesiology, \\ Mahatma Gandhi Medical College and Research Institute, Puducherry, India.
}

\begin{abstract}
Background: Instrumental vaginal delivery is a major concern during epidural labour analgesia. In previous studies levobupivacaine $0.1 \%$ was associated with increase in instrumental vaginal delivery when compared to $0.1 \%$ ropivacaine. Reducing the concentration of levobupivacaine may decrease the incidence of instrumental delivery. Hence, we compared $0.08 \%$ levobupivacaine and $0.1 \%$ ropivacaine with fentanyl as adjuvant for epidural labour analgesia in terms of mode of delivery.
\end{abstract}

Methods: This prospective randomised controlled trial was conducted on 70 nulliparous parturients with singleton uncomplicated pregnancy. They were randomized into two groups to receive $0.08 \%$ levobupivacaine or $0.1 \%$ ropivacaine with $2 \mu \mathrm{g} / \mathrm{ml}$ fentanyl as intermittent epidural boluses. The epidural analgesia was initiated with $12 \mathrm{ml}$ of study drug solution in active stage of labour and was maintained by repeated demand boluses whenever the Visual Analogue Scale (VAS) score was $>3$. Onset, duration and quality of analgesia, degree of motor blockade was analysed. Primary outcome measure was the mode of delivery. Onset and duration of analgesia and Apgar score of baby were the secondary outcomes.

Results: Instrumental vaginal delivery was $6.45 \%$ in levobupivacaine(L) and $4.54 \%$ in ropivacaine(R) group. However, $11.4 \%$ and $37.1 \%$ parturients underwent caesarean section in group $\mathrm{L}$ and group $\mathrm{R}$ respectively $(\mathrm{p}=0.012 * *)$. Mean onset of analgesia and duration of analgesia was comparable. More than $80 \%$ of parturients had excellent pain relief in both the groups with good baby APGAR score.

Conclusion: We conclude that $12 \mathrm{ml}$ of intermittent epidural boluses of $0.08 \%$ levobupivacaine and $0.1 \%$ ropivacaine with $2 \mu \mathrm{g} / \mathrm{ml}$ fentanyl (equipotent dose) provided equal and effective analgesia during labour with comparable incidence of instrumental vaginal delivery.

Key words: Instrumental vaginal delivery; levobupivacaine; labour analgesia; ropivacaine; quality of analgesia

\section{Introduction}

Epidural labour analgesia (EA) is known to be associated with operative delivery, instrumental assisted deliveries and prolonged labour. With the use of minimum local anaesthetic concentration (MLAC) and opioids as additives, many studies had proved that EA is not associated

*Correspondence: Annie J Sheeba

E mail: annie.john24@yahoo.co.in

https://orcid.org/0000-0003-1993-9256

Received: 02/01/2018

Accepted:06/05/2018

DOI: http://doi.org/10.4038/slja.v26i2.8309

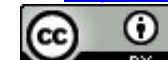

with increased caesarean section (CS) rate ${ }^{1}$ but discussions regarding its influence on instrumental vaginal delivery $(\text { IVD })^{2}$ and duration of labour ${ }^{3}$ still persists thereby affecting the neonatal outcome. ${ }^{4}$

Kumar et $\mathrm{al}^{5}$ found that the incidence of IVD was $32 \%$ with $0.1 \%$ levobupivacaine and none with ropivacaine. Studies have been done with $0.0625 \%$ levobupivacaine for labour analgesia but found that frequent additional rescue drug was required to produce satisfactory analgesia. ${ }^{6,7}$ Hence, we compared the effectiveness of $0.1 \%$ ropivacaine and $0.08 \%$ levobupivacaine with fentanyl as adjuvant for epidural labour analgesia in terms of mode of delivery. 


\section{Methodology}

Following approval from the institutional ethical committee, this prospective randomized doubleblind study was conducted at a tertiary medical college hospital. All pregnant nulliparous women admitted to the Department of Obstetrics and Gynaecology for confinement and who requested for labour analgesia from December 2015 to May 2017 were invited to participate in the study. Detailed education about epidural labour analgesia and explanation about the study protocol was given to the parturients.

Seventy primigravidae, ASA I and II, age between 18yrs to $32 \mathrm{yrs}$ with singleton pregnancy with vertex presentation were included in the study. All those parturients who were high risk pregnancies, CPD, foetal anomaly, and any contraindications for neuraxial block (local anaesthetic toxicity, injection site infection, coagulopathy and spine abnormalities) were excluded from the study. Parturients who were willing to participate in the study were selected by convenient sampling and they were randomized to one of the two groups levobupivacaine (A) and ropivacaine (B) by sealed envelope technique. Written informed consent was obtained from all the participants.

During early stage of labour, acid aspiration prophylaxis was given intravenously and the parturient was shifted to operating room and connected to standard monitors (pulse- oximetry, noninvasive blood pressure, ECG) and the base line values were noted. Preloading was done with $500 \mathrm{ml}$ of Ringers' lactate solution using 18G peripheral venous cannula. Following strict aseptic precautions, epidural space was identified in left lateral position at $\mathrm{L}_{2}-\mathrm{L}_{3}$ or $\mathrm{L}_{3}-\mathrm{L}_{4}$ with an 18G Touhy needle (Perifix, B-Braun Epidural catheter kit) using loss of resistance to air technique and $18 \mathrm{G}$ multi-orifice epidural catheter was threaded cephalad and fixed with $4-5 \mathrm{~cm}$ of the catheter within the space. After confirming negative aspiration to blood or CSF, epidural test dose was given with $3 \mathrm{ml}$ of $1.5 \%$ lignocaine with $15 \mu \mathrm{g}$ adrenaline. Ruling out intravascular and intrathecal placement, the catheter was secured and the parturient was shifted back to labour ward. Pain was assessed by using VAS of $10 \mathrm{~cm}$ from 0-10 and initial VAS score was assessed.

Study by Kumar et $\mathrm{al}^{7}$ showed that the incidence of instrumental delivery with $0.1 \%$ levobupivacaine was $32 \%$ and nil with $0.1 \%$ ropivacaine. We hypothesised that by reducing the concentration of levobupivacaine to $0.08 \%$ (equipotent dose), there will be a reduction in instrumental delivery by $80 \%$. To compare the two groups, with alpha error of 0.05 and beta error of $80 \%$ the sample size required was 31 in each group. We took a sample size of 35 to allow for withdrawals from study during labour.

Patients were divided into two groups of 35 each. Patients in group-A $(\mathrm{n}=35)$ received $12 \mathrm{ml}$ of $0.08 \%$ levobupivacaine with $2 \mu \mathrm{g} / \mathrm{ml}$ fentanyl and group-B $(\mathrm{n}=35)$ received $12 \mathrm{ml}$ of $0.1 \%$ ropivacaine with $2 \mu \mathrm{g} / \mathrm{ml}$ fentanyl as an adjuvant to their study solution. The study solutions were prepared aseptically by an anaesthetist who was not directly involved in this study. When the parturient went in to an active stage of labour (cervical dilation $>$ or $=3 \mathrm{~cm}$ ) standard monitoring was started and the epidural analgesia was initiated during contraction free period in supine position over a period of 2-3min. The time of the injection of the initial dose was kept as time zero and assessments were scheduled accordingly. The adequacy of analgesia was assessed at every $5 \mathrm{~min}$ intervals and analgesia was considered adequate if the VAS reduced to $<3$. The onset of analgesia was defined as time from the first dose to the time of achieving VAS $<3$. If analgesia was inadequate in $30 \mathrm{~min}$ after the initial dose, an additional $12 \mathrm{ml}$ of the same drug solution was injected and VAS score was assessed. If analgesia is further inadequate, alternative mode of analgesia was provided after consulting with attending anaesthetist and the case was excluded from the study. Fifteen minutes after adequate analgesia was achieved, quality of analgesia was assessed by verbal scoring system (0-no pain, 1- aware of contractions but not painful, 2-aware of pressure but tolerable discomfort, 3- distressing pain or pressure) and motor blockade was assessed using a Modified Bromage Score. All parturients with motor blockade score-0 was given a supervised trial walk to assess their ability to ambulate and were encouraged to ambulate until obstetrician augmented the labour. Whenever parturient complained of pain (VAS >3) epidural top-up was given with $12 \mathrm{ml}$ of the same study solution. During the second stage of labour, top ups were given in sitting posture if required. Haemodynamic parameters of mother (oxygen saturation, pulse rate, blood pressure), and foetal heart rate (FHR) was monitored at $10 \mathrm{~min}$ 
intervals throughout the study. Pruritus, nausea, sedation was assessed at $30 \mathrm{~min}$ intervals.

The mode of delivery, and the indication for instrumental delivery/caesarian section, was noted. Neonatal assessment was done with Apgar score of the baby at the $1^{\text {st }}$ and $5^{\text {th }}$ minutes. One hour after the delivery of the baby, the mother was enquired about their satisfaction regarding labour analgesia on a 4-point scale. 3- excellent pain relief, 2- good pain relief, 1- fair pain relief and 0 - poor pain relief.

During the study period hypotension was defined as systolic blood pressure of $<90 \mathrm{mmHg}$ and was treated with an intravenous bolus of $6 \mathrm{mg}$ mephenteramine. Heart rate $<60 \mathrm{bpm}$, was treated with an i.v. bolus dose of $0.6 \mathrm{mg}$ atropine sulfate. If parturient went for cesarean section, epidural anaesthesia was achieved with $12 \mathrm{ml}$ of $2 \%$ lignocaine with adrenaline.

All data was entered into a Data Collection Proforma Sheet (MS Excel 2011).

Student $t$ test was used for quantitative data such as demographics, duration of analgesia, haemodynamic parameters. Since the quantitative data was not normally distributed for onset of analgesia, Mann Whitney U test was used. Chi- square test was used for mode of delivery and side- effects. Mann Whitney U test was used to analyze quality of analgesia, degree of motor blockade, foetal outcome and maternal satisfaction.

Statistical analysis was carried out using SPSS version 20.0 (IBM SPSS, US) software with Regression Modules installed. Descriptive analyses were reported as mean and standard deviation of continuous variables.

\section{Results}

The mean age (Group L $24.2 \pm$ 3years, Group R $23.7 \pm 3$ years) weight (Group L $73.46 \pm 7.8 \mathrm{~kg}$ and $75.94 \pm 8 \mathrm{~kg}$ in Group R) and height (Group $\mathrm{L} 156.86 \pm 5.86 \mathrm{~cm}$ and group R $158.09 \pm 5.06$ $\mathrm{cm}$ ) of parturients in both the groups were comparable.
Figure 1: Incidence of instrumental vaginal delivery with levobupivacaine and ropivacaine Percentage of instrumental vaginal delivery

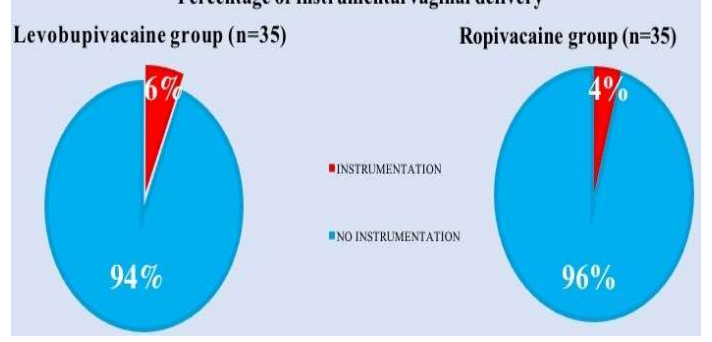

The incidence of instrumental vaginal delivery was comparable and statistically not significant $(\mathrm{P}=0.739)$

Figure 2: Percentage of caesarean section with levobupivacaine and ropivacaine

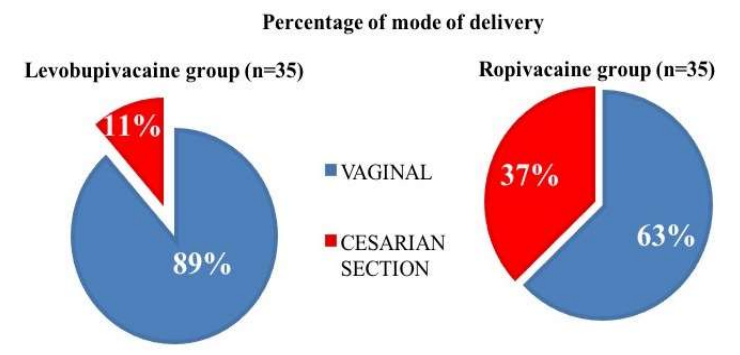

In levobupivacaine group 4 parturients and in ropivacaine group 13 underwent caesarean section which was statistically significant $(\mathrm{p}=0.012 * *)$

Table 1: Comparison of secondary outcome variables between the two groups

\begin{tabular}{|l|l|l|l|}
\hline $\begin{array}{l}\text { Variables } \\
\text { (minutes) }\end{array}$ & $\begin{array}{l}\text { Levobupivacaine } \\
\text { (mean 95\%CI) }\end{array}$ & $\begin{array}{l}\text { Ropivacaine } \\
\text { (mean } \\
\mathbf{9 5 \%}\end{array}$ & $\begin{array}{l}\text { P } \\
\text { value }\end{array}$ \\
\hline $\begin{array}{l}\text { Onset of } \\
\text { analgesia }\end{array}$ & $\begin{array}{l}22.43 \pm 2.6 \\
(21.75-23.29)\end{array}$ & $\begin{array}{l}21.00 \pm 2.5 \\
(20.17-21.83)\end{array}$ & 0.37 \\
\hline $\begin{array}{l}\text { Duration } \\
\text { of } \\
\text { analgesia }\end{array}$ & $\begin{array}{l}67.2 \pm 9.7 \\
(66.34-68.06)\end{array}$ & $\begin{array}{l}66.0 \pm 12 \\
(62.02-69.98)\end{array}$ & 0.66 \\
\hline $\begin{array}{l}\text { Duration } \\
\text { of labour }\end{array}$ & $\begin{array}{l}289.5 \pm 176.5 \\
(286.29-292.71)\end{array}$ & $\begin{array}{l}272.5 \pm 171.1 \\
(215.81-\end{array}$ & 0.747 \\
\hline
\end{tabular}

Onset of analgesia $(\mathrm{p}=0.37)$, duration of epidural analgesia $(p=0.66)$, duration of labour $(p=0.747)$ were comparable and statistically not significant between the two groups. 
Figure 3: Comparison of quality of analgesia between levobupivacaine and ropivacaine

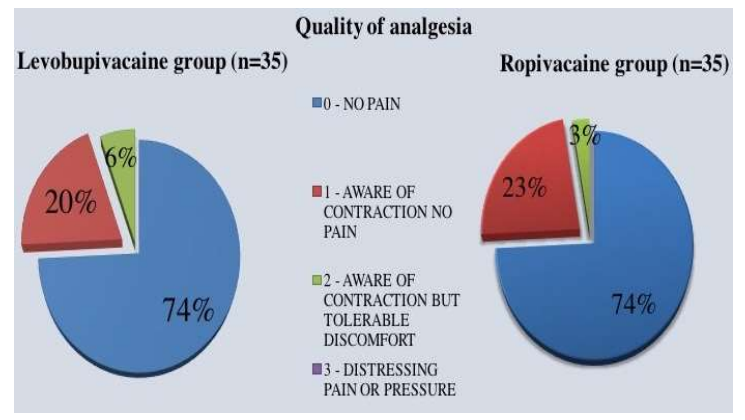

In either group no parturients had distressing pressure or pain during uterine contractions. Quality of analgesia was comparable between the levobupivacaine and ropivacaine groups.

Figure 5: Comparison of maternal satisfaction between levobupivacaine and ropivacaine

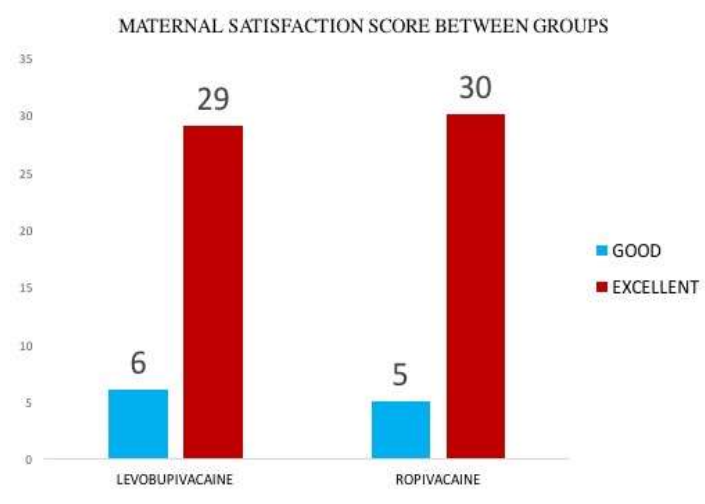

Maternal satisfaction score was excellent in almost $80 \%$ of parturients in both the groups. None in either group complained of poor pain relief.

The maternal heart rate was stable in both levobupivacaine and ropivacaine groups throughout the study period. Only 5\% of parturients had sinus tachycardia (rise of more than $20 \%$ from base line) and was attributed to the use of intravenous valethamate bromide for augmenting the cervical dilatation. In both levobupivacaine and ropivacaine group there was no significant change in blood pressure (mean arterial pressure). In both the groups all new borns had good Apgar score of more than seven at one and nine at five minutes.

\section{Discussion}

Labour analgesia is still an unmet right for parturients in India because of lack of parturient awareness and myths and controversies among the providers such as increased risk of instrumentation ${ }^{8}$ and operative delivery. ${ }^{9}$ Previous studies have shown that the rate of instrumental vaginal delivery depends on several confounding factors such as the dose and concentration of the epidural solution used, ${ }^{10}$ the degree of analgesia during second stage, ${ }^{11}$ and obstetric factors. Reduction of serum oxytocin levels can result in a weakening of uterine activity. ${ }^{12}$ Maternal efforts at expulsion can also be impaired, causing foetal malposition during descent. ${ }^{13}$ Previously, the association of neonatal morbidity and mortality with longer labour (second stage longer than two hours) had justified expediting delivery, leading to increased rates of instrumental delivery. ${ }^{14}$

Increased rates of instrumental vaginal delivery are important as it increases the risk of maternal perineal trauma ${ }^{15}$ and in cases of difficult mid forceps delivery increases the risk of adverse neonatal outcomes. ${ }^{16}$ As such, minimizing the risk of instrumental vaginal delivery while maximizing patient comfort is an art and a science, requiring diligence by the anaesthesia provider to the individual needs of each parturient.

Purdie et $\mathrm{al}^{17}$ compared $0.1 \%$ levobupivacaine and $0.1 \%$ ropivacaine with fentanyl by PCEA for labour analgesia and found $50 \%$ instrumental vaginal delivery with ropivacaine and $32 \%$ with levobupivacaine. Kumar et $\mathrm{al}^{5}$ compared the same drug with same concentration by intermittent bolus technique and found similar $32 \%$ instrumental vaginal delivery with levobupivacaine but nil in ropivacaine group and they attributed the cause to be pelvic floor muscle laxity caused by more potent levobupivacaine than ropivacaine in equal concentrations. There is no literature available regarding $0.08 \%$ levobupivacaine with fentanyl for labour analgesia. Hence, we reduced the concentration of levobupivacaine and studied its effects on the incidence of instrumental vaginal delivery (IVD) in comparison to $0.1 \%$ ropivacaine.

In our study we found that the incidence of IVD (low outlet forceps) was $6.45 \%$ with levobupivacaine group and $4.54 \%$ with ropivacaine group and was not statistically significant. On analyzing the indications for 
instrumentation, they were face to pubis delivery in two parturients in levobupivacaine group and poor maternal effort in one parturient in ropivacaine group. Lieberman et $\mathrm{al}^{18}$ in his prospective cohort study found that epidural analgesia was associated with significantly higher incidence of occcipito posterior fetus position at delivery. A meta-analysis done by Brancato et $a{ }^{19}$ found that delayed pushing effort by the mother encouraged passive descent of the foetal head during $\mathrm{II}^{\text {nd }}$ stage of labour and had significant positive effects on increased incidence of the spontaneous vaginal deliveries, and decreased instrument-assisted vaginal deliveries associated with shortened pushing time with EA and the same was suggested by Miller as early as 1997. With increasing use of continuous electronic foetal monitoring, a longer but more comfortable labour may cause little harm to the neonate. Updated Cochrane database $2017^{20}$ and ACOG guidelines (2017) on obstetric analgesia also recommends delaying the pushing of parturient till full dilatation of cervix to enhance the rotation of foetal head.

In our study we observed that the incidence of CS was significantly higher in ropivacaine group $\left(p=0.012^{* *}\right)$. The indications of the CS were meconium stained liquor, foetal distress, cord prolapse, arrest of dilatation and deep transverse arrest. The time interval between last epidural top-up and foetal distress was more than 50mins and with a stable blood pressure. However earlier studies by Purdie et $\mathrm{al}^{17}$ and Kumar et $\mathrm{al}^{7}$ showed no difference in incidence of CS rates with $0.1 \%$ of both levobupivacaine and ropivacaine with fentanyl.

In our study, we found that the mean onset of analgesia and the mean duration of analgesia was comparable between the two drugs but Kumar et $\mathrm{al}^{5}$ found a statistically significant difference in the mean onset and mean duration of analgesia with $0.1 \%$ levobupivacaine and ropivacaine but did not find any clinical significance.

Parturients did not have motor blockade and they had stable haemodynamics in both groups and comparable duration of labour. Analysis of quality of analgesia during peak uterine contraction was a unique factor of the study and $74 \%$ parturients categorised it as excellent (parturients did not perceive the discomfort produced by uterine contraction). All newborns had good Apgar scores. In our study the maternal satisfaction score was done one hour after the delivery of the baby and we observed that $>80 \%$ of mothers in either of the groups (levobupivacaine and ropivacaine) had excellent satisfaction score for pain relief which was similar to Purdie et al. ${ }^{17}$

\section{Conclusion}

We conclude that $12 \mathrm{ml}$ of intermittent epidural boluses of $0.08 \%$ levobupivacaine and $0.1 \%$ ropivacaine with $2 \mathrm{mcg} / \mathrm{ml}$ fentanyl provide equal and effective analgesia during labour with reduced and comparable maternal outcome in terms of instrumental vaginal delivery.

\section{Strength of the study}

Robust methodology with randomisation and double blinding

\section{Limitations}

Obstetricians with varied experiences managed our parturients and decision making regarding mode of delivery was subjective to their skill and possible effect of these drugs on each stage of labour was not analysed.

\section{Suggestions for future research}

For further studies on labour analgesia, we would suggest that studies should be directed to assess the parturient anxiety level and knowledge about labour process before institution of labour analgesia and the obstetrician working experience and attitude towards labour analgesia and its effect on labour outcome.

\section{References}

1. Wassen MMLH, Hukkelhoven CWPM, Scheepers HCJ, Smits LJM, Nijhuis JG, Roumen FJME. Epidural analgesia and operative delivery: a ten-year population-based cohort study in The Netherlands. Eur J ObstetGynecolReprod Biol 2014; 183:125-31. https://doi.org/10.1016/j.ejogrb.2014.10.023 PMid:25461365

2. Sengar S, Ohary R. Observation on Effects of Lumbar Epidural Analgesia for Painless Labor. Int J Sci Stud 2016;3(12):244-7.

3. Agrawal D, Makhija B, Arora M, Haritwal A, Gurha P. The Effect of Epidural Analgesia on Labour, Mode of Delivery and Neonatal Outcome in Nullipara of India, 2011-2014. J ClinDiagn Res JCDR2014;8(10):OC03-OC06.

PMid:25478409 PMCid:PMC4253227

4. Hasegawa J, Farina A, Turchi G, Hasegawa Y, Zanello M, Baroncini S. Effects of epidural analgesia on labor length, instrumental delivery, 
and neonatal short-term outcome. J Anesth 2013;27:43-7.

https://doi.org/10.1007/s00540-012-1480-9 PMid:22965331

5. Kumar TS, Rani P, Kumar VH, Samal S, Parthasarathy S, Ravishankar M. Quality of labor epidural analgesia and maternal outcome with levobupivacaine and ropivacaine: A doubleblinded randomized trial. Anesth Essays Res 2017;11(1):28.

https://doi.org/10.4103/0259-1162.194573

PMid:28298752 PMCid:PMC5341640

6. Lee H-L, Lo L-M, Chou C-C, Chuah E-C, others. Comparison between $0.08 \%$ ropivacaine and $0.06 \%$ levobupivacaine for epidural analgesia during nulliparous labor: a retrospective study in a single center. Chang Gung Med J 2011;34(3):286-92.

PMid:21733358

7. Hamada T, Baba M, Sato M, Saito T, Murakami K, Sumikura H. Comparison between $0.06 \%$ and $0.1 \%$ Levobupivacaine Combined with $2 \mu \mathrm{g} / \mathrm{mL}$ of Fentanyl for Epidural Labor Analgesia. Open J Anesthesiol 2013;03(9):379-82. https://doi.org/10.4236/ojanes.2013.39080

8. Antonakou A, Papoutsis D. The effect of epidural analgesia on the delivery outcome of induced labour: a retrospective case series. Obstetrics and Gynecology International Volume 2016; Article ID 5740534: 5 pages.

9. Hussain SST, Maheswari P. Barriers for labour analgesia in South India - Knowledge and attitude of relevant stakeholders: A hospital-based crosssectional study. Indian J Anaesth 2017;61(2):170-3.

https://doi.org/10.4103/0019-5049.199848 PMid:28250488 PMCid:PMC5330076

10. Comparative Obstetric Mobile Epidural Trial (COMET) Study Group UK, "Effect of low-dose mobile versus traditional epidural techniques on mode of delivery: a randomised controlled trial," The Lancet 2001; 358:19-23. https://doi.org/10.1016/S0140-6736(00)05251-X

11. Bates RG, Helm CW, Duncan A, Edmonds DK. Uterine activity in the second stage of labour and the effect of epidural analgesia. Br J Obstet Gynaecol 1985;92:1246-50.

https://doi.org/10.1111/j.14710528.1985.tb04870.x

PMid:4084468

12. Goodfellow CF, Hull MG, Swaab DF, Dogterom J, Buijs RM. Oxytocin deficiency at delivery with epidural analgesia. $\mathrm{Br} \mathrm{J}$ Obstet Gynaecol 1983;90:214-9.

https://doi.org/10.1111/j.1471$\underline{0528.1983 . t b 08611 . x}$

PMid:6830729

13. Newton ER, Schroeder BC, Knape KG, Bennett BL. Epidural analgesia and uterine function. Obstet Gynecol 1995;85:749-55
https://doi.org/10.1016/0029-7844(95)00046-T

14. Miller AC. The effects of epidural analgesia on uterine activity and labor. Int $\mathrm{J}$ Obstet Anesth 1997:6:2-18.

https://doi.org/10.1016/S0959-289X(97)80046-5

15. Robinson JN, Norwitz ER, Cohen AP, McElrath TF, Lieberman ES. Episiotomy, operative vaginal delivery, and significant perinatal trauma in nulliparous women. Am J Obstet Gynecol 1999;181:1180-4. https://doi.org/10.1016/S0002-9378(99)70104-3

16. Dierker LJ Jr, Rosen MG, Thompson K, Lynn P. Midforceps deliveries: long-term outcome of infants. Am J Obstet Gynecol 1986;154:764-8. https://doi.org/10.1016/0002-9378(86)90452-7

17. Purdie NL, McGrady EM. Comparison of patientcontrolled epidural bolus administration of $0.1 \%$ ropivacaine and $0.1 \%$ levobupivacaine, both with $0.0002 \%$ fentanyl, for analgesia during labour. Anaesthesia2004;59(2):133-7. https://doi.org/10.1111/j.1365-2044.2004.03582.x PMid: 14725515

18. Lieberman E, Davidson K, Lee-Parritz A, Shearer E. Changes in fetal position during labor and their association with epidural analgesia. Obstet Gynecol 2005;105(5):974-82.

https://doi.org/10.1097/01.AOG.0000158861.43593.49 PMid: 15863533

19. Brancato RM, Church S, Stone PW. A meta-analysis of passive descent versus immediate pushing in nulliparous women with epidural analgesia in the second stage of labor. J ObstetGynecol Neonatal Nurs 2008;37(1):4-12.

https://doi.org/10.1111/j.1552-6909.2007.00205.x PMid:18226152

20. Lemos A, Amorim MM, Dornelas de Andrade A, de Souza AI, Cabral Filho JE, Pushing/bearing down methods for the second stage of labour. Cochrane DatabaseSystRev2017;3:CD009124.

https://doi.org/10.1002/14651858.CD009124.pub3 